\title{
Human decidua-associated protein hDP200 appears to be a rheumatoid factor
}

\author{
R. Halperin, P. Kraicer and E. Hadas* \\ Department of Zoology, Tel Aviv University, Tel Aviv, Israel
}

\begin{abstract}
The amino acid sequences of the amino-terminal of the two different polypeptide chains of the human decidua-associated protein hDP200, with apparent molecular masses of 55 and $25 \mathrm{kDa}$, were determined. The amino-terminal sequence of the $55 \mathrm{kDa}$ chain revealed that it is an immunoglobulin heavy chain, of the $\mathrm{V}_{\mathrm{H}}$-III subgroup and the amino-terminal sequence of the $25 \mathrm{kDa}$ chain showed that it is a human kappa V-III light chain. The sequence data indicate that hDP200 is an immunoglobulin. The ability of the hDP200 molecules to form high molecular weight complexes with immunoglobulins of other classes suggest that hDP200 is a rheumatoid factor.
\end{abstract}

\section{Introduction}

Endometrial decidualization involves growth and differentiation of a 'new', progestagen-dependent tissue, the decidua, which gradually replaces the functional layer of the endometrium. Pregnancy is not mandatory for growth and differentiation of decidual tissue: it is produced in each normal cycle in the late luteal phase in response to progesterone. The decidua is shed at birth or menstruation. As decidualization involves growth and differentiation of new tissue, the appearance of decidua-associated proteins would be expected.

Halperin et al. (1990a) described the identification, immunopurification by a monoclonal antibody and partial characterization of an apparently novel decidua-associated protein which was named according to its molecular weight in non-reducing SDS-PAGE analysis as hDP200. SDS-PAGE analysis performed under reducing conditions, revealed that hDP200 is composed of two polypeptide chains of apparent molecular masses of $55 \mathrm{kDa}$ and $25 \mathrm{kDa}$, which were accordingly named hDP55 and hDP25, respectively. We now report that as deduced from amino-terminal sequence information of both polypeptide chains, hDP200 appears to be an immunoglobulin. hDP200 is probably a rheumatoid factor as it has the capacity to interact with other human immunoglobulins.

\section{Materials and Methods}

Monoclonal antibody, immunoaffinity purification and western blot analysis

The preparation and characterization of $\mathrm{mAB}$ DEC21, immobilization of the antibody on Eupergit $C$ beads (Rohm, Darmstadt), performance of immunoaffinity purification and western blot analysis were performed as described by Halperin

\footnotetext{
${ }^{*}$ Current address and address for correspondence: Interpharm Laboratories, Industrial Park, Ness-Ziona, Israel 76500.

Received 7 May 1993.
}

et al. (1990a). Briefly, Eupergit C beads were washed with phosphate-buffered saline (PBS) and with $1.0 \mathrm{~mol}$ potassium phosphate buffer $\mathrm{I}^{-1} \mathrm{pH}$ 7.5. Monoclonal antibody dissolved in the above buffer was added to the beads and the mixture was agitated by rotation for $16 \mathrm{~h}$ at $4^{\circ} \mathrm{C}$. Residual oxirane groups were blocked by reacting them with $1 \mathrm{~mol}$ ethanolamine $\mathrm{I}^{-1}$ at $\mathrm{pH} 9.5$ for $4 \mathrm{~h}$ at $4^{\circ} \mathrm{C}$. The $\mathrm{mAb}$-Eupergit $\mathrm{C}$ conjugated beads were packed into a column and washed extensively with PBS. The column was loaded with crude decidual extract $\left(2.5 \mathrm{ml} \mathrm{ml}^{-1}\right.$ of column) and then the column was washed extensively with PBS. Bound proteins were eluted with $1 \mathrm{~mol}$ ammonium acetate buffer $1^{-1} \mathrm{pH} 10.0$, neutralized, concentrated to $1 \mathrm{ml}$ using a centriflo $\mathrm{CF} 25$ ultrafiltration membrane cone (nominal molecular mass cut-off $25 \mathrm{kDa}$; Amicon, Danvers, MA) and dialysed against PBS. Protein concentration was determined by the method of Bradford (1976).

\section{Double-site enzyme-linked immunosorbentassay}

Enzyme-linked immunosorbentassay (ELISA) plates were

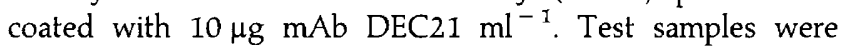
diluted in PBS containing 5\% BSA and incubated in wells for I h at $37^{\circ} \mathrm{C}$. MAb DEC2I conjugated with horseradish peroxidase (Tijssen, 1986) was added and the plates were incubated for $1 \mathrm{~h}$ at $37^{\circ} \mathrm{C}$. Activity of the bound horseradish peroxidase was determined with 0 -phenylenediamine $\left(2 \mathrm{mg} \mathrm{ml}^{-1}\right)$ and $\mathrm{H}_{2} \mathrm{O}_{2}(0.008 \%)$ in $50 \mathrm{mmol}$ citrate buffer $\mathrm{I}^{-1} \mathrm{pH} 5.0$. The reaction was stopped by the addition of $50 \mu \mathrm{l} 4 \mathrm{mmol} \mathrm{HCl} \mathrm{I}^{-1}$.

\section{Polyacrylamide gel electrophoresis blotting and amino-terminal sequencing}

Electrophoresis was performed under reducing conditions as described by Laemmli (1970). Purified hDP200 was separated by SDS-PAGE and blotted onto a PVDF membrane (Millipore, Bedford, MA) treated with polybren (Applied Biosystems, Foster City, CA) (Xu and Shively, 1988). The blotted protein 


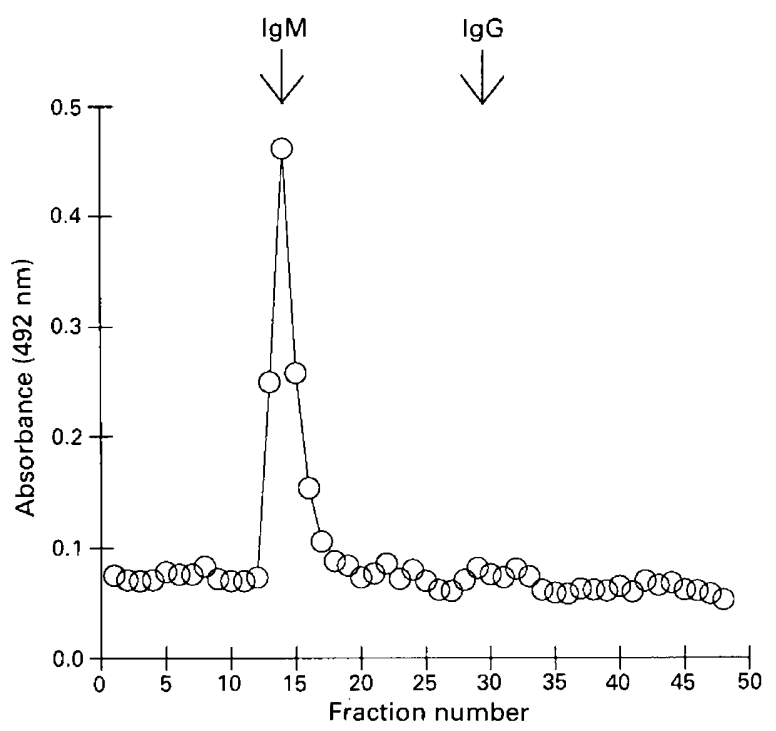

Fig. 1. Analysis of the apparent molecular mass of hDP200 in menstrual fluid by size exclusion chromatography. A crude menstrual fluid specimen was subjected to chromatography on a column of Sepharose $4 \mathrm{~B}$, and fractions were collected and probed for the presence of hDP 200 by double site ELISA.

bands were visualized by Coomassie blue staining. The stained protein bands were cut out and submitted to sequencing, using the Applied Biosystems 470A gas-phase microsequencer. Computer comparisons were carried out by National Biological Research Foundation database.

\section{Gel filtration on Sepharose $4 B$}

Samples were separated on Sepharose 4B (Pharmacia, Uppsala) column $(1.2 \mathrm{~cm} \times 40 \mathrm{~cm})$, equilibrated with PBS, at a flow rate of $0.5 \mathrm{ml} \mathrm{min}{ }^{-1}$. Fractions of $1 \mathrm{ml}$ were collected. The fractions obtained were probed by the double-site ELISA for $\mathrm{hDP} 200$.

\section{Results}

The decidua-associated protein hDP200 was purified by immunoaffinity chromatography on a column prepared from $\mathrm{mAb}$ DEC21. hDP200 was copurified with hDP71 (Halperin et al., 1990b). The preparation was separated by SDS-PAGE and blotted onto a PVDF membrane. The hDP55 and hDP25 protein bands were excised and amino-terminal sequencing was performed. The resulting sequence for hDP55 was: Glu-ValGly/Gln-Leu-Val-Glu-Ser-Gly-*-*-Leu-Val-Gln-Pro-Gly. This sequence is identical to the sequence of the Human Ig gamma heavy chain of the $\mathrm{V}_{\mathrm{H}}$-III subgroup which is: Glu-Val-Gln-LeuVal-Glu-Ser-Gly-Gly-Asp-Leu-Val-Gln-Pro-Gly. The resulting sequence for hDP25 was: Glu-Ile-Val/Gly-Leu/Met-Thr-GlnSer-Pro-Gly/Ala-Thr-Leu. This sequence is identical to the sequence of the human kappa light chain of the $\mathrm{V}$-III subgroup which is: Glu-Ile-Val-Leu-Thr-Gln-Ser-Pro-Gly-Thr-Leu. The above results indicate that $\mathrm{hDP} 200$ is an immunoglobulin. The monoclonal antibody DEC21 recognizes an antigenic determi-

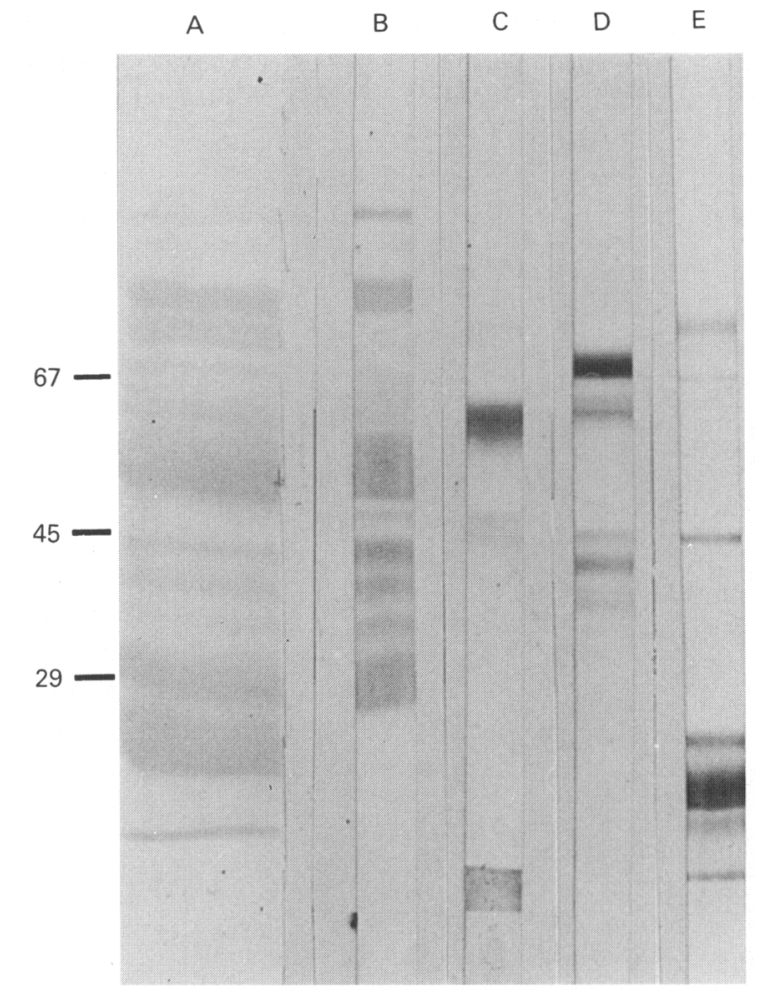

Fig. 2. A western blotting analysis demonstrating that hDP200 is complexed with non-IgG immunoglobulins. Immunoaffinity purified hDP200 from menstrual fluid was separated by SDS-PAGE, and blotted onto a nitrocellulose membrane. Detection of the bound antibodies was performed using a second antibody conjugated with horseradish peroxidase (HRP) and the HRP chromogenic substrate chloronaphthol. (A) Staining for total proteins with Ponceau S, (B) staining with anti-human $\gamma$ heavy chain, (C) staining with anti-human $\alpha$ heavy chain, (D) staining with anti-human $\mu$ heavy chain, (E) staining with anti-human kappa light chain.

nant that is specific to the hDP200 and is not found on serum derived immunoglobulins.

A double site ELISA for hDP200 was established. MAb DEC21 was used as both the capture and detector antibody. When this ELISA was used hDP200 was detected and quantified in decidual extracts (12 samples), uterine washes (over 200 samples), amniotic fluids (17 samples), menstrual fluid samples (over 250 samples) and seminal fluid samples (five samples).

The determinants recognized by $m A b s$ usually appear only once in polypeptide chains. The success of the double site ELISA therefore implied that the antigenic species recognized in the ELISA is a multi-molecular complex of hDP200 and perhaps additional molecules. The presence of the putative complexes in crude menstrual fluid was demonstrated by subjecting a crude menstrual fluid sample to chromatography on Sepharose 4B column and the fractions containing hDP200 were identified by the ELISA (Fig. 1). The activity of hDP200 was eluted from the column in a high molecular mass fraction $(>900 \mathrm{kDa})$ and not at the expected molecular mass of $150 \mathrm{kDa}$ typical for immunoglobulins. This finding supports the idea that the antigenic species identified by the ELISA exists as a complex containing at least two units of hDP200. hDP200 was purified from crude menstrual fluid by 
immunoaffinity chromatography using $\mathrm{mAb}$ DEC21. Identification of the proteins in the immunoaffinity purified preparation of hDP200 by westem blotting analysis (Fig. 2) revealed heavy chains of $\operatorname{IgG}, \operatorname{Ig} A$ and $\operatorname{IgM}$ and kappa light chains. Thus, apparently, the putative complexes formed by the hDP200 contains IgG (the hDP200) and also IgA and IgM.

\section{Discussion}

Analysis of hDP200 revealed that it is an IgG. The heavy chain is of the $\mathrm{V}_{\mathrm{H}}$-III subgroup and the kappa light chain is of the $\mathrm{V}$-III subgroup. The kappa light chain of the V-III subgroup is found in a high percentage of monoclonal rheumatoid factors (Kunkel et al., 1974; Newkirk et al., 1986). The presence of a light chain of the V-III subgroup in hDP200 therefore indicates that it is a monoclonal rheumatoid factor. MAb DEC21, which was used for identification and immunoaffinity purification of $\mathrm{hDP} 200$, recognizes a specific determinant of $\mathrm{hDP} 200$ that is not found on other immunoglobulins. Further support for the contention that hDP200 is a rheumatoid factor is the discovery that hDP 200 forms complexes with other immunoglobulins of the IgM and IgA classes.

There are no previous reports of the presence of an Ig binding protein or rheumatoid factor in the uterus. Several Ig binding proteins were described in the seminal plasma (Witkin et al., 1983; Thaler et al., 1989; Liang et al., 1991) but none was identified as an immunoglobulin. The observations reported here indicate that the distribution of Ig-binding proteins, rheumatoid factor or other, is common to both the male as well as the female genital systems. Cells bearing the surface antigen Leu-1 (CD5) produce rheumatoid factors in humans (Hardy et al., 1987). This cell type is probably similar to murine lymphocytes, bearing the cell surface antigen Ly-I (Casali et al., 1987). Lymphocytes, bearing the Ly-I marker, were identified in murine decidual tissues (Lala et al., 1986). It is therefore reasonable to assume that homologous cells, bearing the Leu- 1 marker would be found in the human decidua and produce the rheumatoid factor(s) found in the human decidual tissue.

The physiological function of the rheumatoid factor found in the human uterus is currently unknown. However, it is possible that it serves as one of the mechanisms that ensures suppression of the immune response toward sperm cells and the fetus.

\section{References}

Bradford MM (1976) A rapid and sensitive method for the quantitation of protein utilizing principle of protein-dye binding Analytical Biochemistry $\mathbf{7 2}$ 248-254

Casali P, Burastero SE, Nakamura M, Inghiramin G and Notkins AL (1987) Human lymphocytes making rheumatoid factor and antibody to ssDNA belong to Leu- ${ }^{+}$B-cell subset Science 236 77-80

Halperin R, Hadas R, Fleminger G, Ovadia Y and Kraicer PF (1990a) Identification, immunoaffinity purification and partial characterization of a human decidua-associated protein Journal of Reproduction and Fertility 88 159-165

Halperin R, Fleminger G, Ovadia Y, Kraicer PF and Hadas R (1990b) Identification, immunoaffinity purification and initial characterization of a novel $71 \mathrm{kDa}$ human decidua associated protein by use of specific monoclonal antibodies Tissue and Cell 22 779-784

Hardy RR, Hayakawa K, Shimizu M, Yamasaki K and Kishimoto T (1987) Rheumatoid factor secretion from human Leu-1 ${ }^{+}$B-cells Science 236 81-83

Kunkel H, Winchester RJ, Joslin FG and Capra JD (1974) Similarities in the light chain of the anti-immunoglobulins showing cross-idiotypic specificities Joumal of Experimental Medicine 139 128-136

Laemmli UK (1970) Cleavage of structural proteins during the assembly of the head of bacteriophage T4 Nature 227 680-685

Lala PK,. Parhar RS, Kearns M, Johnson S and Scodras JM (1986) Immunologic aspects of the decidual response. In Reproductive Immunology pp 190-198 Eds DA Clark and BA Leroy. Elsevier, Amsterdam

Liang ZG, Kamada M and Koide SS (1991) Structural identity of immunoglobulin binding factor and prostatic secretory protein of human seminal plasma Biophysical and Biochemical Research Communication 180 356-359

Newkirk M, Chen PP, Carson D, Rosnett D and Capra JD (1986) Amino acid sequence of a light chain variable region of a human rheumatoid factor of the Wa idiotypic group in part predicted by its reactivity with anti-peptide antibodies Molecular Immunology 23 239-244

Thaler CJ, Faulk WP and McIntyre JC (1989) Soluble antigens of IgG receptor Fc $\gamma$ RIII in human seminal plasma Journal of Immunology 143, 1937-1942

Tijssen P (1986) Preparation of enzyme-antibody or other enzymemacromolecule conjugates. In Practice and Theory of Enzyme Immunoassay p 221 Eds RH Burdan and PH van Knippenberg. Elsevier, Amsterdam

Witkin SS, Richard JM, Bongiovanni AN and Zelikovsky G (1983) An IgG-FC binding protein in seminal fluid American joumal of Reproductive Immunology $323-27$

Xu QY and Shively JE (1988) Microsequence analysis of peptides and proteins. VIII. Improved electroblotting of proteins onto membranes and derivatized glass-fiber sheets Analytical Biochemistry 170 19-30 